\title{
The effect of a copper intra-uterine contraceptive device on the microbial ecology of the female genital tract
}

\author{
K. M. ELHAG, A. M. BAHAR* and A. A. MUBARAK† \\ Departments of Microbiology, 'Obstetrics and Gynaecology, Faculty of Medicine, Kuwait University P.O. Box \\ 24923 Safat, 13110 Kuwait and +Maternal Welfare Clinic, Kuwait
}

\begin{abstract}
Summary. Bacteria isolated from 108 intra-uterine contraceptive devices (IUCD) removed from patients with pelvic inflammatory disease (PID), haemorrhage, pregnancy and from asymptomatic women, and from the genital tracts of 66 healthy controls not wearing an IUCD, were studied. No significant differences were found in the types of micro-organisms or isolation rates from IUCDs removed from women in the various clinical groups. The isolation rate of anaerobic bacteria from IUCDs removed from asymptomatic wearers was significantly lower than that from controls, with the exception of the isolation rate of actinomyces which was significantly higher in IUCD wearers and $A$. israelii was recovered only from IUCDs. The isolation rates of the different bacterial species varied with the duration of the device in utero. The presence of a copper IUCD altered the bacterial flora of the female genital tract. The insertion of such a device and the ecological changes that follow play a crucial role in the development of PID.
\end{abstract}

\section{Introduction}

The requirement for contraception has led to the use of intra-uterine contraceptive devices (IUCD). This method of contraception is not without risk, and reports have shown an increased incidence of pelvic inflammatory disease (PID) amongst women wearing such devices (Nilsson et al., 1981; Duguid et al., 1982). Actinomyces israelii and related species A. naeslundii, A. odontolyticus and Arachnia propionica have been incriminated in these infections (Burkman et al., 1982; Bonnez et al., 1985; Nayar et al., 1985; Peloux et al., 1985). Although Actinomyces spp. are not part of the normal vaginal flora and are rarely recovered from this site, they have been found to colonise the genital tracts of $2 \cdot 8-25 \%$ of women wearing an IUCD (Sykes and Shelley 1981; Burkman et al., 1982; Keebler et al., 1983; Peloux et al., 1985). Some studies showed that these organisms tend to colonise mainly plastic devices and disappear when these are replaced by coppercontaining ones (Duguid et al., 1982; Keebler et al., 1983).

Most of these findings were based on the detection of Actinomyces spp. on Papanicolaou-stained cervico-vaginal smears and by immunofluorescence with actinomyces antisera. Other organisms nor-

Received 13 April 1987; accepted 13 May 1987. mally present in the vagina may resemble actinomyces in Papanicolaou smears (Rogosa et al., 1974) and if antisera have not been tested against a wide range of anaerobes, cross-reactions with other bacterial species may occur (Jones et al., 1979). Attempts were made to culture IUCDs, but the rate of isolation of Actinomyces spp. was low and reports on the types and frequency of other isolates were inconsistent (Hager et al., 1979; Nilsson et al., 1981 ; Sparks et al., 1981; Duguid et al., 1982).

In this study we used improved microbiological techniques to enable us to evaluate the effect of a copper IUCD on the bacterial flora of the female genital tract, the predisposition of wearers to colonisation by Actinomyces spp. and the relationship between bacterial colonisation and gynaecological symptoms.

\section{Materials and methods}

\section{Patients}

One hundred and eight patients who had IUCDs removed during the period June 1984 to May 1986 were studied. They were 21-35 years old with a mean age of 27 years. They were randomly selected from patients referred to the Maternity Hospital and Maternal Welfare Clinics, Kuwait for removal of IUCD. Reasons for removal were PID, haemorrhage, pregnancy, pelvic pain, vaginal 
discharge, desire to conceive or an IUCD in utero for 2 years or more. Each patient was examined for evidence of PID, pregnancy and gynaecological abnormalities.

PID was diagnosed if the patient presented with fever, vaginal discharge and lower abdominal pain, and pelvic tenderness and evidence of adnexitis were found on examination. As shown in table I patients were divided into five groups according to clinical findings: group 1 (15) had PID; group 2 (21) had irregular bleeding; group 3 (10) women were pregnant; group 4 (11) was a miscellaneous group with suprapubic pain (7), vaginal discharge (3), or perforation of the uterus (1); and group 5 comprised (51) asymptomatic IUCD wearers.

\section{Controls}

Sixty-six healthy women attending the Maternity Hospital clinic for advice on contraception, with no contraception or medication for at least 6 months and no gynaecological abnormalities, served as controls. They were $20-37$ years old with a mean age of 28 years.

\section{Contraceptive devices}

The devices removed were copper-containing with monofilament tails (Nova-T, Copper 7, and $\mathrm{Cu} 250$ ). Their duration in utero was 2 weeks to ten years, with a mean of 20.8 months.

\section{Collection of specimens}

Specimens were collected by the two gynaecologist authors. The cervix of each patient was exposed by a sterile bivalve speculum and the ICUD was removed aseptically with sterile forceps without touching the vaginal wall or perineum.

Initially the tails and bodies of 20 IUCDs were processed separately. When no difference was found in the organism isolated, the remaining 88 devices were processed in toto. Specimens from the controls were similarly collected from the endocervix and the posterior fornix with albumin coated swabs. These sites were sampled because they represent areas where an IUCD lies-partly in the endocervix with the filament extending down into the upper vagina. The devices and swabs were placed in anaerobic transport tubes (Portagerm; bioMerieux, Charbonniers-Les-Bains, France) and sent to the microbiology laboratory within $24 \mathrm{~h}$.

\section{Microbiological methods}

Direct plating was not possible because of the irregular structure of the IUCD. The device was soaked in $15 \mathrm{ml}$ of Brain Heart Infusion (BHI) broth (CM225, Oxoid) for $30 \mathrm{~min}$. The broth was shaken for $15 \mathrm{~s}$ and $0.1 \mathrm{ml}$ was inoculated on to each of the following pre-reduced culture media: Blood Agar (CM55, Oxoid), Schaedler Blood Agar (CM437, Oxoid) with kanamycin-vancomycin mixture (55681, bioMerieux) and Schaedler Agar with laked horse blood $5 \% \mathrm{v} / \mathrm{v}$ and gentamicin $80 \mathrm{mg} / \mathrm{L}$. The plates were incubated in an anaerobic system (Model 1028, Forma Scientific, Marietta, OH, USA) with an atmosphere of $\mathrm{N}_{2} 90 \%, \mathrm{H}_{2} 5 \%, \mathrm{CO}_{2} 5 \%$ and examined after 48 and $72 \mathrm{~h}$.

Blood agar and MaConkey Agar (CM7, Oxoid) were similarly inoculated and incubated aerobically for $24 \mathrm{~h}$. The broth containing the IUCD was then incubated anaerobically for $18 \mathrm{~h}$ and subcultured on to pre-reduced blood agar and Schaedler agar with laked horse blood $5 \%$ $\mathrm{v} / \mathrm{v}$ and gentamicin $80 \mathrm{mg} / \mathrm{L}$. The enriched cultures were examined after anaerobic incubation for $72 \mathrm{~h}$. Swabs collected from controls were similarly processed. They were inoculated on to the above solid media and then incubated in BHI broth for $18 \mathrm{~h}$ anaerobically and subcultured as above.

\section{Identification of micro-organisms}

The microbial growth from the specimens and controls was evaluated qualitatively; 5-10 colonies were selected from each plate and indentified. Aerobic bacteria were identified by standard microbiological techniques (Isenberg et al., 1980); anaerobic bacteria were identified on

Table I. Duration of IUCDs in utero and reasons for removal

\begin{tabular}{lccccc}
\hline & \multicolumn{5}{c}{ Number of devices in utero for } \\
\cline { 2 - 6 } & $\begin{array}{c}0-12 \mathrm{~m} \\
\text { Reasons for IUCD removal }\end{array}$ & $\begin{array}{c}13-24 \mathrm{~m} \\
(49)\end{array}$ & $\begin{array}{c}>24 \mathrm{~m} \\
(22)\end{array}$ & $\begin{array}{c}\text { Unknown } \\
(9)\end{array}$ & $\begin{array}{r}\text { Total } \\
(108)\end{array}$ \\
\hline Pelvic inflammatory disease & 4 & 7 & 4 & 0 & 15 \\
Haemorrhage & 8 & 8 & 5 & 0 & 21 \\
Pregnancy & 4 & 3 & 0 & 3 & 10 \\
Pelvic pain & 1 & 3 & 2 & 1 & 7 \\
Vaginal discharge & 0 & 1 & 2 & 0 & 3 \\
Perforation of the uterus & 0 & 0 & 0 & 1 & 1 \\
Retracted thread & 6 & 6 & 2 & 2 & 16 \\
Desire to conceive & 2 & 18 & 7 & 0 & 27 \\
Other causes & 3 & 3 & 0 & 2 & 8 \\
& & & & & \\
\hline
\end{tabular}


the basis of their colonial appearance, cell morphology, biochemically (by the API 20 A system; La Balme Le Grottes, France), and by end products of glucose metabolism as determined by gas-liquid chromatography (Shimatzu Gas Chromatograph, GC-9A, Shimatzu Corp., Kyoto, Japan). Anaerobes were definitively identified according to the scheme of Holdeman et al. (1977).

\section{Statistical analysis}

Analysis of the data was done with the $\chi^{2}$ test.

\section{Results}

Fifteen $(13.9 \%)$ patients with IUCDs were diagnosed clinically as having PID. There was no correlation between the duration of the device in utero and the occurrence of infection (table I). The micro-organisms isolated from IUCDs from the various clinical groups and controls are shown in table II. Actinomyces spp. and Arachnia propionica were isolated from $16(14.8 \%)$ devices, $A$. israeli most commonly $(9 \cdot 3 \%$, whereas $A$. viscosus and $A$. odontolyticus were isolated from only two controls $(3 \%)$. Lactobacillus spp. were isolated from 10 $(9 \cdot 3 \%)$ devices and from $25(37.9 \%)$ controls, and anaerobic cocci from $13(12.8 \%)$ devices and 24 $(36.4 \%)$ controls. Bacteroides spp. were isolated from $15(13.8 \%)$ devices; three $(2.8 \%)$ isolates were $B$. fragilis. The Bacteroides strains isolated from the $12(18 \cdot 2 \%)$ controls were $B$. disiens, $B$. bivius and $B$. melaninogenicus; $B$. fragilis was not isolated from this group. Staphylococcus spp. and Streptococcus spp. were the most common aerobic isolates from devices and controls, followed by enterobacteria and Candida spp. Gardnerella vaginalis was isolated from controls only. There was no significant difference in either the types or the isolation rates of micro-organisms from devices removed from women in the different clinical groups.

Fig. 1 shows the micro-organisms isolated from IUCDs removed from asymptomatic wearers and

Table II. Micro-organisms isolated from IUCDs removed from clinical groups and from normal controls

\begin{tabular}{|c|c|c|c|c|c|c|c|}
\hline \multirow[b]{2}{*}{ Micro-organism } & \multicolumn{6}{|c|}{ Number of isolates from groups of IUCD wearers } & \multirow{2}{*}{$\begin{array}{c}\text { and } \\
\text { controls } \\
\text { (66) }\end{array}$} \\
\hline & $\begin{array}{l}\text { PID } \\
(15)\end{array}$ & $\begin{array}{l}\text { Haemorrhage } \\
\text { (21) }\end{array}$ & $\begin{array}{l}\text { Pregnancy } \\
(10)\end{array}$ & $\begin{array}{l}\text { Misc. } \\
(11)\end{array}$ & $\begin{array}{l}\text { Asymp. } \\
\text { (51) }\end{array}$ & $\begin{array}{c}\text { All } \\
(108)\end{array}$ & \\
\hline \multicolumn{8}{|l|}{ ANAEROBIC BACTERIA } \\
\hline \multicolumn{8}{|l|}{ Actinomyces and Arachnia } \\
\hline A. israelii & 3 & 1 & 2 & 1 & 3 & 10 & 0 \\
\hline A. viscosus & 1 & 0 & 0 & 0 & 2 & 3 & 1 \\
\hline A. naeslundii & 0 & 0 & 0 & 0 & 1 & 1 & 0 \\
\hline A. odontolyticus & 0 & 0 & 0 & 0 & 0 & 0 & 1 \\
\hline Ar.propionica & 0 & 0 & 0 & 1 & 1 & 2 & 0 \\
\hline \multicolumn{8}{|l|}{ Other gram-positive bacilli } \\
\hline Bifidobacterium spp. & 0 & 0 & 0 & 0 & 1 & 1 & 0 \\
\hline Eubacterium spp. & 0 & 2 & 0 & 1 & 2 & 5 & 10 \\
\hline Lactobacillus spp. & 1 & 2 & 2 & 3 & 2 & 10 & 25 \\
\hline \multicolumn{8}{|l|}{ Gram-negative bacilli } \\
\hline B. fragilis & 1 & 0 & 1 & 0 & 1 & 3 & 0 \\
\hline Other species of the fragilis group & 1 & 1 & 0 & 0 & 0 & 2 & 0 \\
\hline B. melaninogenicus & 0 & 0 & 0 & 0 & 2 & 2 & 2 \\
\hline Other Bacteroides spp. & 3 & 2 & 0 & 1 & 2 & 8 & 10 \\
\hline Fusobacterium spp. & 0 & 2 & 0 & 0 & 3 & 5 & 5 \\
\hline \multicolumn{8}{|l|}{ Anaerobic cocci } \\
\hline Peptococcus spp. & 3 & 2 & 1 & 0 & 3 & 9 & 18 \\
\hline Peptostreptococcus spp. & 1 & 1 & 0 & 1 & 1 & 4 & 6 \\
\hline \multicolumn{8}{|l|}{ AEROBIC BACTERIA } \\
\hline Staphylococcus spp. & 2 & 11 & 6 & 2 & 18 & 39 & 17 \\
\hline Streptococcus gp. B & 4 & 3 & 0 & 1 & 9 & 17 & 12 \\
\hline Other streptococci & 3 & 3 & 1 & 1 & 4 & 12 & 7 \\
\hline Corynebacterium spp. & 0 & 1 & 2 & 1 & 3 & 7 & 3 \\
\hline Escherichia coli & 1 & 1 & 1 & 1 & 5 & 9 & 6 \\
\hline Other enterobacteria & 1 & 0 & 0 & 2 & 5 & 8 & 5 \\
\hline Gardnerella vaginalis & 0 & 0 & 0 & 0 & 0 & 0 & 2 \\
\hline Candida spp. & 0 & 3 & 0 & 4 & 8 & 15 & 7 \\
\hline
\end{tabular}




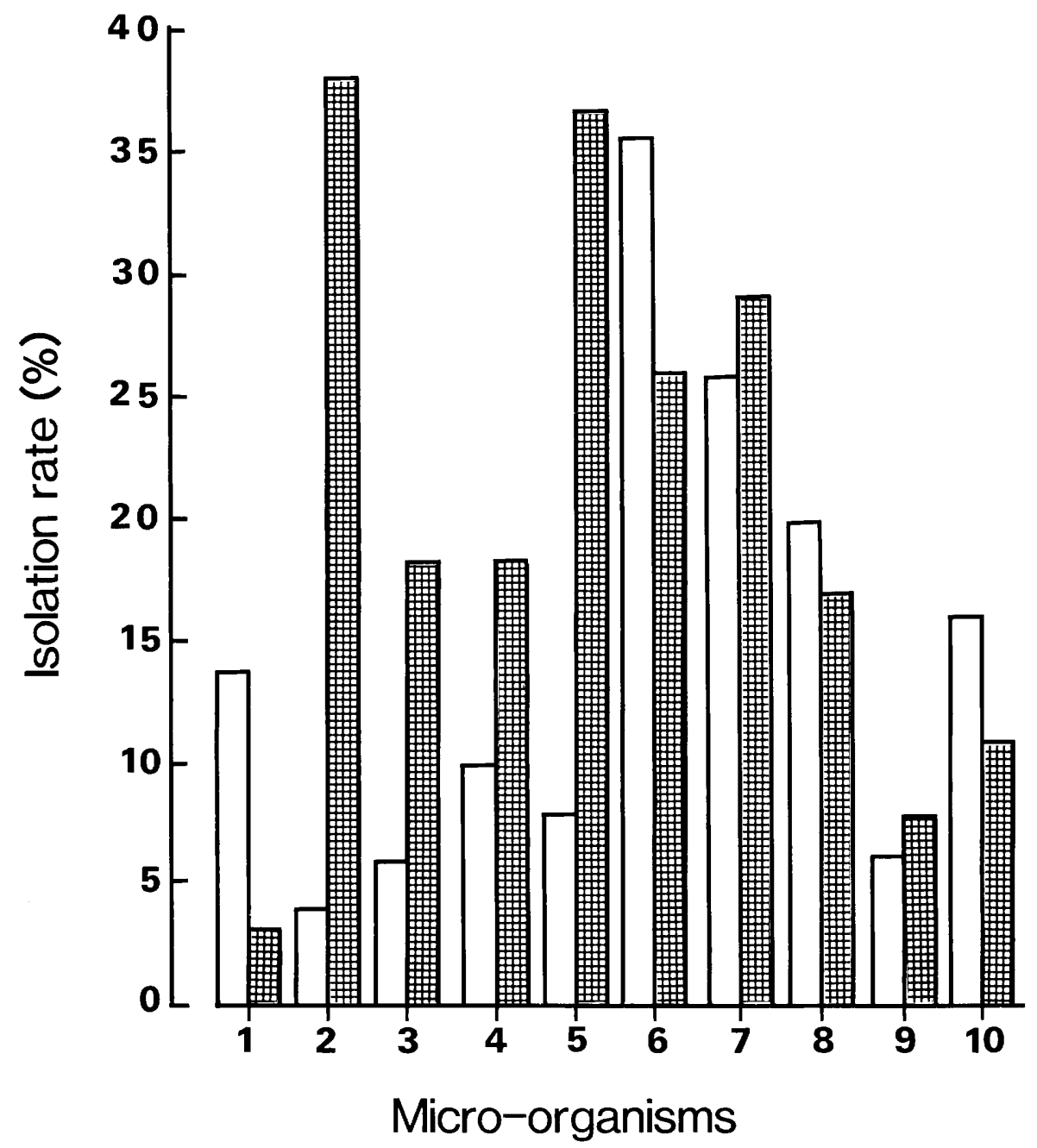

Fig. 1. Micro-organisms isolated from IUCDs removed from asymptomatic women ( $\square$ ) and from control women (曲). 1. Actinomyces spp. and Ar. propionica; 2. Lactobacillus spp.; 3. Other anaerobic gram-positive bacilli; 4. Bacteroides spp.; 5. Anaerobic cocci; 6. Staphylococcus spp.; 7. Streptococcus spp.; 8. Enterobacteria; 9. Other aerobic bacteria; 10. Candida spp.

those from the genital tracts of controls. The isolation rate of anaerobes from the devices was significantly lower than that from the controls $(\mathrm{p}<0.01)$. Actinomyces were isolated from seven $(13.7 \%)$ devices and from only two $(3 \%)$ controls $(\mathrm{p}<0.05)$. A. israelii, A. naeslundii, and Ar. propionica, which were not isolated from any control, were isolated from IUCDs at a frequency of three $(5.9 \%)$, one $(2 \%)$ and one $(2 \%)$ respectively. Lactobacilli, on the other hand, were isolated from only two $(3.9 \%)$ devices, compared to $25(37.9 \%)$ controls $(\mathrm{p}<0.01)$. The other anaerobic gram positive bacilli and anaerobic cocci were also isolated with higher frequency from the controls $(p<0 \cdot 05)$. No significant difference was found in the rates of isolation of Bacteroides spp. or aerobic bacteria between devices and controls.

The isolation rates of micro-organisms related to duration of IUCD in utero and compared with controls are shown in fig. 2. The isolation rate of actinomyces between devices worn for less than 1 year and the controls was not significantly different, but was significantly higher from devices worn for $1-2$ years, $(p<0.01)$ and from those worn for over 2 years $(p<0.01)$. Lactobacilli were isolated from devices worn for $<1$ year, $1-2$ years and $>2$ years at a significantly lower rate than from the controls $(p<0.01)$. Anaerobic cocci were not isolated from any device in situ for $<1$ year, but their isolation rate increased steadily with the duration of wearing 


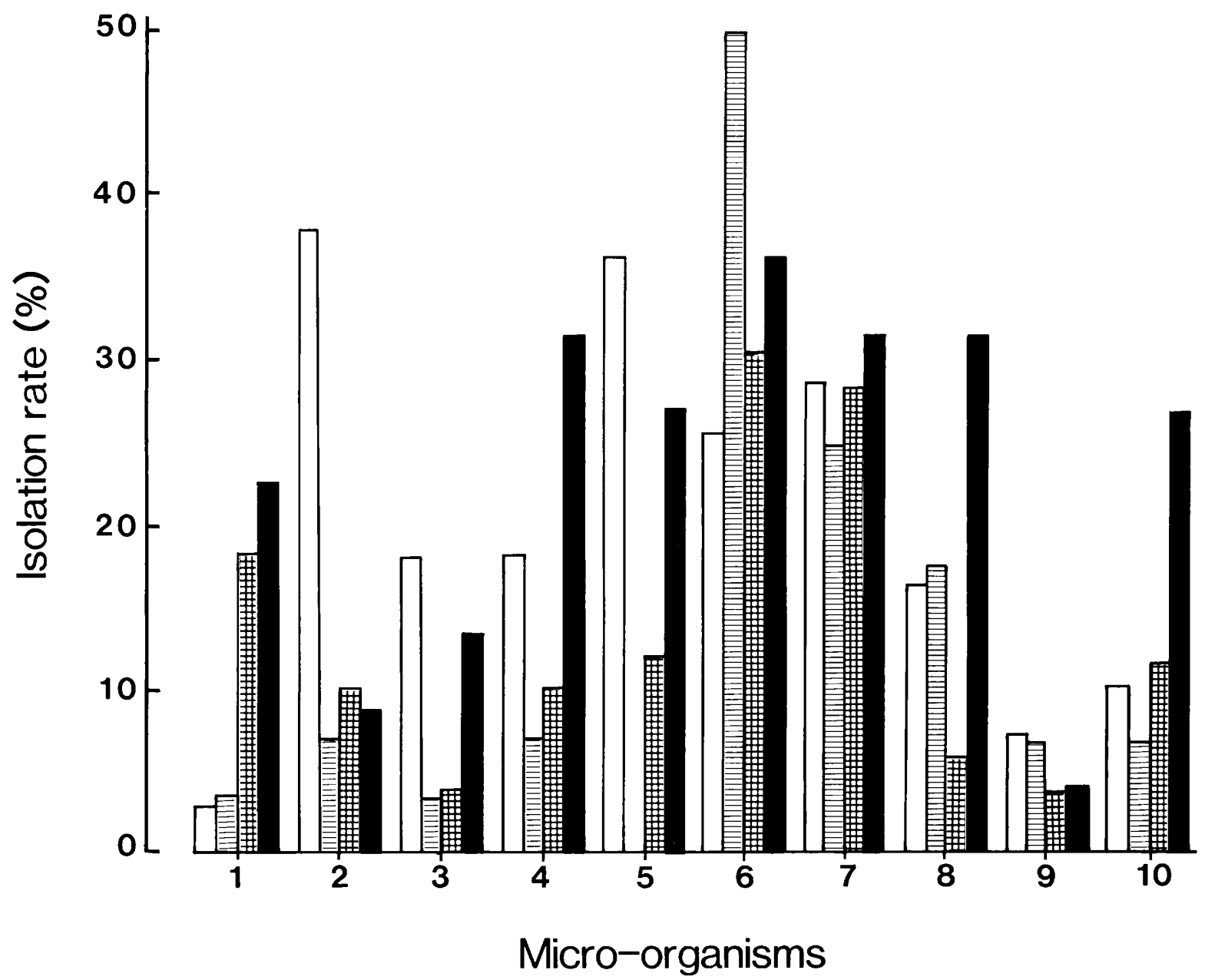

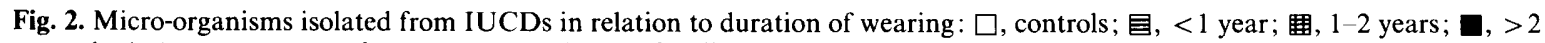
years. 1. Actinomyces spp. and Ar. propionica; 2. Lactobacillus spp.; 3. Other anaerobic gram-positive bacilli; 4. Bacteroides spp.; 5. Anaerobic cocci ; 6. Staphylococcus spp.; 7. Streptococcus spp.; 8. Enterobacteria; 9. Other aerobic bacteria; 10. Candida spp.

$(12.2 \%$ and $27.3 \%$ in $1-2$ and $>2$ years use respectively). The isolation rates of aerobic bacteria from devices removed from the various clinical groups and from the genital tracts of the controls were similar, except for enterobacteria which were isolated at a significantly higher rate $(\mathrm{p}<0 \cdot 05)$ from devices worn for $>2$ years.

\section{Discussion}

Fifteen $(13.8 \%)$ IUCD wearers were found to have PID and a further 10 had symptoms (vaginal discharge or pain) without clinical evidence of infection. No significant difference was found in the rate of isolation of the various bacterial species between patients in the different clinical groups.
This makes incrimination of a particular organism in these infections difficult to justify, and suggests that several factors such as the micro-organisms, the state of the host, and others, are responsible for the development of PID.

Generally, anaerobic bacteria were isolated from devices at a significantly lower rate than from controls. This is in contrast to the findings of several workers (Dische et al., 1974; Hager et al., 1979; Nayar et al., 1985) some of whom have attributed the proliferation of anaerobes in their series to the reducing effect of copper. Our findings suggest that copper has a detrimental effect on gram-positive anaerobes with the exception of Actinomyces spp., which were apparently favoured by its presence. The antibacterial effect of copper is known (Waler 
and Rölla, 1982) and reports have shown that following insertion such devices release about $27 \mu \mathrm{g}$ of copper daily and this amount decreases with time (Chantler et al., 1984). The varying concentration of copper and the degree of susceptibility of these bacteria may explain the difference in the isolation rates of various bacterial species in relation to the duration of IUCD wearing. The absence of actinomyces from devices worn for $<1$ year, which could be due to high copper concentration, led Duguid et al. (1982) to conclude that actinomyces disappeared from the genital tract following the replacement of plastic devices by copper-containing ones. Perhaps, had further examination been done in subsequent years, actinomyces could have been isolated.

Actinomyces spp. and $A r$. propionica were recovered from $14.8 \%$ devices, a finding comparable to those detected on smears (Hager et al., 1979; Burkman et al., 1982; Keebler et al., 1983), but greater than those reported by culture (Hager et al., 1979; Sparks et al., 1981) This may be attributed to improved techniques used in transporting and processing specimens. Similar to other reports (Hager et al., 1979; Burkman et al., 1982; Duguid et al., 1982; Nayer et al., 1985), A. israelii was the anaerobe most frequently isolated from IUCDs in our study and was not isolated from any controls. The same applied to the related species, $A$. naeslundii, and $A r$. propionica (Bonnez et al., 1985; Nayer et al., 1985). Incriminating primarily $A$. israelii in IUCD-associated PID, Duguid et al. (1982) reported a correlation between the duration of IUCD in utero and the occurrence of infection. In our study no such correlation could be established, but the isolation of actinomyces increased with the duration of IUCD in situ. The presence of these organisms probably represents simple colonisation and their isolation from an IUCD may not necessarily indicate infection, an observation consistent with other reports (Luff and Gupta, 1977; Jones et al., 1979). Although there was no significant difference in the isolation rate of Bacteroides spp.

\section{REFERENCES}

Bonnez W, Lattimer G, Mohanraj N A, Johnson T H 1985 Actinomyces naeslundii as an agent of pelvic actinomycosis in the presence of an intrauterine device. Journal of Clinical Microbiology 21:273-275.

Burkman R, Schlesselman S, McCaffrey L, Gupta P K, Spence M 1982 The relationship of genital tract actinomycetes and the development of pelvic inflammatory disease. American Journal of Obstetrics and Gynecology 143:585-589.

Chantler E N et al. 1984 Degradation of the copper-releasing from devices and controls, they showed a tendency to proliferate in devices in situ for $>2$ years. Furthermore, the potential pathogen, B. fragilis, was isolated only from devices. Lomax et al. (1976), isolated B. fragilis and Peptostreptococcus spp. from cases of IUCD-associated PID and Elhag et al. (1987) demonstrated specific $B$. fragilis antibodies in sera from patients with PID. Enterobacteria and anaerobic cocci showed a similar trend to Bacteroides spp. The combination of bacteroides and enterobacteria in mixed infections is well documented (Gorbach and Bartlett, 1974).

Other factors may contribute to the development of PID. According to Eschenbach (1983), lactobacilli, with other vaginal bacteria, play a protective role by producing an acidic environment incompatible with the growth of many pathogens and their inhibition would promote the multiplication of various potential pathogens. Hanna et al. (1985) found an association between a high vaginal $p \mathrm{H}$ and the prevalence of pathogenic micro-organisms in vaginal secretions. Furthermore the insertion of an IUCD breaches the protective barrier of cervical mucus and the IUCD tail creates a transmission link between the sterile uterine cavity and the bacteria-rich vagina. Sparks et al. (1981) were able to demonstrate the migration of vaginal bacteria into the uterine cavity via the appendages of the device. The isolation of similar organisms from both the device and the filament in our cases gives further confirmation of those findings.

In conclusion, the present study confirms earlier findings that an IUCD promotes colonisation by Actinomyces spp., and further suggests that the presence of such a foreign body and the ecological changes it triggers, play a crucial role in the development of infection and that organisms other than actinomyces could be implicated in IUCDassociated PID.

This study was supported by Kuwait University Research Council (Grant no. MI 007). We thank Miss Aleyamma Alex and Mrs Aleyamma Pazhoor for technical assistance, and Dr A. Senthilselvan for statistical analysis.

intrauterine contraceptive device and its significance British Journal of Obstetrics and Gynaecology 91 : 172-181.

Dische F E, Burt J M, Davidson N J H, Puntambekar S 1974 Tubo-ovarian actinomycosis associated with intrauterine contraceptive devices. Journal of Obstetrics and Gynaecology of the British Commonwealth 81 : 724-729.

Duguid H L D et al. 1982 Studies on uterine tract infections and the IUCD with special reference to actinomycetes. British Journal of Obstetrics and Gynaecology Suppl. 4:32-40.

Elhag K M, Bahar A M, Mahajan K K 1987 Difficulties in the serodiagnosis of infection with the fragilis group of Bacteroides. Journal of Medical Microbiology 24:125-131. 
Eschenbach D A 1983 Vaginal infection. Clinics in Obstetrics and Gynecology 26: 186-202.

Gorbach S L, Bartlett J G 1974 Anaerobic infections (First of three parts). New England Journal of Medicine 290:11771184.

Hager W D et al. 1979. Pelvic colonization with actinomyces in women using intrauterine contraceptive device. American Journal of Obstetrics and Gynecology 135:680-684.

Hanna N F, Taylor-Robinson D, Kalodiki-Karamanoli M, Harris J R W, McFadyen I R 1985 The relationship between vaginal $\mathrm{pH}$ and the microbiological status in vaginitis. British Journal of Obstetrics and Gynaecology 92:1267-1271.

Holdeman L V, Cato E P, Moore W E C (eds) 1977 Anaerobic laboratory manual, 4 th edn. Anaerobe Laboratory, Virginia Polytechnic Institute and State University, Blacksburg, VA, USA.

Isenberg $\mathrm{H} \mathrm{D}$, Washington $\mathrm{J} \mathrm{A}$, Ballows $\mathrm{A}$, Sonnenwirth A C 1980 Collection, handling and processing of specimens. In: Lenette $\mathrm{E} \mathrm{H}$ et al. (eds) Manual of clinical microbiology, 3rd edn. American Society for Microbiology, Washington DC pp 52-82.

Jones M C, Buschmann B O, Dowling E A, Pollock H M 1979 The prevalence of Actinomycetes-like organisms found in cervicovaginal smears of 300 IUD wearers. Acta Cytologica 23: 282-286.

Keebler C, Chatwani A, Schwartz R 1983 Actinomycosis infection associated with intrauterine contraceptive devices. American Journal of Obstetrics and Gynecology 145: $596-599$.

Lomax C W, Harbert G M, Thornton W N 1976 Actinomycosis of the female genital tract. Obstetrics and Gynecology 48: $341-346$.
Luff R D, Gupta P K 1977 Actinomycetes-like organisms in wearers of intrauterine contraceptive devices. American Journal of Obstetrics and Gynecology 129:476-477.

Nayar M, Chandra M, Chitraratha K, Kumari Das S, Rai Chowdhary G 1985 Incidence of actinomycetes infection in women using intrauterine contraceptive devices. Acta Cytologica 29:111-116.

Nilsson C G, Vartiainen E, Widholm O 1981 Bacterial cultures from intrauterine devices removed from patients with pelvic inflammatory disease. Acta Obstetrica et Gynecologica Scandanavica 60: 563-566.

Peloux Y, Raoult D, Chardon H, Escarguel J P 1985 Actinomyces odontolyticus infections: review of six patients. Journal of Infection 11 : $125-129$.

Rogosa M, Cumminis C S, Lelliott R A, Keddie R M 1974 Actinomycetes and related organisms. In: Buchanan $\mathrm{R} E$, Gibbons N E (eds) Bergeys manual of determinative bacteriology, 8th edn. Williams and Wilkins, Baltimore, MD, USA.

Sparks R A, Purrier B G A, Watt P J, Elstein M 1981 Bacteriological colonization of uterine cavity: role of tailed intrauterine contraceptive device. British Medical Journal 282:1189-1191.

Sykes G S, Shelley G 1981 Actinomyces-like structures and their association with intrauterine contraceptive devices, pelvic infection and abnormal cervical cytology. British Journal of Obstetrics and Gynaecology 88: 934-937.

Waler S M, Rölla G 1982 Comparison between plaque inhibiting effect of chlorhexidine and aqueous solutions of copperand silver-ions. Scandanavian Journal of Dental Research 90: $131-133$. 